\title{
Transthoracic occlusion for secundum atrial septal defects unsuitable for transcatheter occlusion approach
}

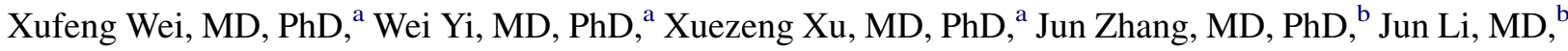 \\ Shiqiang $\mathrm{Yu}, \mathrm{MD}, \mathrm{PhD},{ }^{\mathrm{a}}$ and Dinghua $\mathrm{Yi}, \mathrm{MD}, \mathrm{PhD}^{\mathrm{a}}$
}

\begin{abstract}
Objective: Transcatheter occlusion of secundum atrial septal defects is a safe and effective alternative to traditional surgical closure; however, it is associated with serious occasional complications and inapplicable to more than $20 \%$ of atrial septal defects. In 2000, transthoracic occlusion was pioneered at Xijing Hospital as a novel method of atrial septal defect closure. The purpose of this study is to report the early and mid-term results of the transthoracic occlusion procedure and to evaluate its safety and efficacy.
\end{abstract}

Methods: From April 2000 to April 2006, 268 patients with atrial septal defects were classified into 2 groups: group A (unsuitable for transcatheter occlusion, $\mathrm{n}=126)$ and group $\mathrm{B}(\mathrm{n}=142)$. The transthoracic occlusion method used transesophageal echocardiographic-guided atrial septal defects occluder deployment via a right minithoracotomy without cardiopulmonary bypass or fluoroscopy.

Results: Device implantation was successful in 265 patients (98.9\%), including 9 elliptical devices in group A. The average size of circular occluders in group A was $38.2 \pm 4.2 \mathrm{~mm}$, which was larger than in group B (24.0 \pm $4.5 \mathrm{~mm})(P<.001)$. The average procedure time was $37.2 \pm 9.2$ minutes, the average intracardiac manipulation time was $5.8 \pm 3.0$ minutes, and the average inpatient stay was $3.2 \pm 0.8$ days. Twenty-five complications $(9.3 \%)$ occurred in patients during the follow-up period. No large residual shunting, device embolization, or other severe complications resulted from transthoracic occlusion.

Conclusions: Transthoracic occlusion is a new safe and effective method for atrial septal defect treatment, even for patients with partial atrial septal defects unsuitable for transcatheter occlusion. This hybrid method broadens the indications of atrial septal defect treatment with device occlusion. (J Thorac Cardiovasc Surg 2011;142:113-9)

The atrial septal defect (ASD) is one of the most common congenital heart defects, occurring in approximately 1 in 1500 live births. ${ }^{1}$ Transcatheter occlusion (TCO) of ASD is a safe, effective alternative to traditional surgical closure, ${ }^{2}$ with many favorable merits, including superior cosmetic results, less trauma, avoidance of cardiopulmonary bypass (CPB), and a shorter hospital stay. ${ }^{3,4}$ However, TCO has still been associated with occasional complications, such as device embolization, residual shunt, vessel injury, and perforation of the heart. ${ }^{5-7}$ Furthermore, not all ASD lesions are treatable by transcatheter closure because of strict inclusion criteria, and as a result, $20 \%$ to $30 \%$ of patients must undergo CPB operation for ASD repair. ${ }^{4,8}$

\footnotetext{
From the Institute of Cardiovascular Surgery ${ }^{\mathrm{a}}$ and Department of Ultrasonography, ${ }^{\mathrm{b}}$ Xijing Hospital, The 4th Military Medical University, Xi'an, Shaanxi Province, P.R. China.

Disclosures: Authors have nothing to disclose with regard to commercial support. Drs Wei and Yi contributed equally to this work.

Received for publication June 7, 2010; revisions received Aug 11, 2010; accepted for publication Oct 16, 2010; available ahead of print Jan 19, 2011.

Address for reprints: Shiqiang $\mathrm{Yu}, \mathrm{MD}, \mathrm{PhD}$, or Dinghua $\mathrm{Yi}, \mathrm{MD}, \mathrm{PhD}$, Institute of Cardiovascular Surgery, Xijing Hospital, the 4th Military Medical University, Xi'an, Shaanxi Province, PR China, 710032 (E-mail: shiqiangyu@gmail.com or dinghuayi@gmail.com).

$0022-5223 / \$ 36.00$

Copyright (C) 2011 by The American Association for Thoracic Surgery

doi:10.1016/j.jtcvs.2010.10.034
}

On April 13, 2000, the Institute of Cardiovascular Surgery successfully performed ASD occlusion via a novel transthoracic occlusion (TTO) implantation method, the first of its kind in the world. ${ }^{9,10}$ By using transesophageal echocardiography (TEE) guidance, this novel method is capable of ASD occlusion via a small 2- to $3-\mathrm{cm}$ incision, without CPB or fluoroscopy. Since the creation of TTO of ASD, with continual improvement of the technique, the procedure has been applied in many institutions in China, which have reported its advantages of safety and efficacy. ${ }^{11,12}$ TTO is particularly advantageous in its suitability for ASD lesions incompatible for TCO repair. From April 2000 to April 2006, we performed TTO of ASD in 268 patients, including 126 patients deemed unsuitable for TCO treatment. This retrospective study, with the early and mid-term follow-up results, analyzes the safety and efficacy of TTO for isolated secundum ASDs, especially for patients unfit for TCO.

\section{METHODS AND MATERIALS \\ Patient Population}

From April 2000 to April 2006, 268 patients underwent transthoracic closure of ASD. ASD was diagnosed in these patients by transthoracic echocardiography performed by 2 experienced echocardiographers (board-certified ultrasonography attending physicians) who were consulted by senior interventional cardiologists and cardiovascular surgeons experienced in TTO. The ASD closure method was chosen by specialist 

Abbreviations and Acronyms
$\mathrm{ASD}=$ atrial septal defect
$\mathrm{CPB}=$ cardiopulmonary bypass
$\mathrm{ICU}=$ intensive care unit
$\mathrm{TCO}=$ transcatheter occlusion
$\mathrm{TEE}=$ transesophageal echocardiography
$\mathrm{TTO}=$ transthoracic occlusion

recommendation and the patient or guardian. Table 1 lists the inclusion criteria for patients undergoing TTO and TCO. All patients undergoing TTO were divided into 2 groups (A and B). Group A consisted of 126 patients: 120 patients who were deemed unsuitable for TCO repair by Table 1 criteria and 6 patients who previously failed ASD closure by TCO attempt. Group B consisted of 142 patients who satisfied the TCO repair criteria but chose TTO repair. All patients were fully informed about TTO and gave consent before the operation. The ethics committee of our hospital approved the use of the TTO technique of ASD closure.

\section{Operation Preparation}

TTO was performed in the cardiothoracic operation room, where CPB was readily available if necessary. Each patient underwent general anesthesia with tracheal intubation in the supine position.

\section{Transesophageal Echocardiography}

TEE was performed by experienced echocardiographers (board-certified ultrasonography attending physicians) who confirmed the anatomic details of each individual ASD case, determined the size and type of occlusion device needed, and verified the feasibility of TTO success. TEE garnered anatomic details, such as the maximum ASD longitudinal and horizontal diameters, as well as the rim measurements from the defect margins to important surrounding structures, such as the aortic root, coronary sinus, atrioventricular valves, right pulmonary vein, superior vena cava, and inferior vena cava. TEE also assessed the floppiness of the interatrial septum and the hardness of the surrounding ASD rim tissue. Floppy interatrial septum or soft ASD rim tissues require larger occluder devices to ensure a positive seal and prevent shunt or leak. If the TEE identified ASD morphology dissimilar from earlier preoperative transthoracic echocardiography and the patient no longer fit TTO inclusion criteria as a result, the patient would be prepared for conventional open surgical intervention directly.

\section{Devices and Occluders Selection}

The simple delivery system consisted of a straight sheath and a cable (Ke Wei Medical Apparatus Co, Dongguan, China). Occluders from 2 manufacturers (APAC Scientific International Co, and Ke Wei Medical Apparatus Co, Beijing, China) were used in our study. Both circular and elliptical occluders (both double-disc) are available and similar to the Amplatzer (AGA Medical Corp, Plymouth, Minn) septal occluder in design, but they possess harder rims. A sizing balloon is unnecessary in TTO. Proper occluder size is selected by adding 3 to $5 \mathrm{~mm}$ to the maximum ASD diameter for a round-type ASD. For elliptical or large size ASDs, a special elliptical occluder $4 \mathrm{~mm}$ larger than the maximum longitudinal diameter is chosen. For rims diagnosed as being soft by TEE, an additional $2 \mathrm{~mm}$ was added to the chosen occluder size.

\section{Implantation Technique}

The supine patient was padded below the right shoulder and lower right lumbar region with approximately $20-\mathrm{cm}$ foam support. An incision approximately 2.0 to $3.0 \mathrm{~cm}$ was made in the right anterior fourth intercostal space, immediately laterally to the sternum. Sufficient exposure was achieved with a mini-retractor. Heparin drip was then initiated at $1.0 \mathrm{mg} / \mathrm{kg}$, and bedside testing of the patient's blood was performed. We ensured that the patient had an activated clotting time more than 200 seconds before device deployment. The pericardium was incised approximately $2 \mathrm{~cm}$ superior to the phrenic nerve and suspended with four 1-0 silk sutures. Two parallel purse-string sutures of 3-0 or 4-0 Prolene (Ethicon, Inc, Somerville, NJ) were placed on the right atrium. The selected occlusion device was fixed into a straight sheath. A right atrial puncture was made within the purse-string sutures, and the sheath was inserted. Under TEE guidance, the sheath was advanced through the defect into the left atrium. By advancing the delivery cable, the atrial disc was extruded and adjusted to be parallel with the atrial septum. Both sheath and cable were withdrawn until the occlusion disc joined the atrial septum. ASD occlusion was confirmed by the disappearance of any left to right shunt detectable by TEE. Before the device was released, the occlusion disc's stability was confirmed via a repeated push-pull maneuver. If TEE revealed any obvious residual shunting, an unstable occlusion disc, or a disc encroaching on adjacent structures, the device was redeployed and repositioned. If satisfactory ASD occlusion was achieved, the sheath was withdrawn, and the purse-string sutures were tied. The initial thoracic incision was closed without drainage tube placement (Figure 1, $A-H$ ).

\section{Perioperative Evaluation and Follow-up}

All patients were transferred to the intensive care unit (ICU) for recovery and monitoring postoperatively. All patients underwent baseline clinical examination, electrocardiography, chest radiography, and transthoracic echocardiography before surgery; as inpatients postoperatively before discharge; at 1, 3, and 12 months postdischarge; and annually thereafter. Anti-aggregation therapy consisted of heparin (administered during the first 24 hours postoperatively) and aspirin $(3-4 \mathrm{mg} / \mathrm{kg} / \mathrm{d}$, continued for 6 months postoperatively).

\section{Statistical Analysis}

For nominal values, data are expressed as a frequency or percentage; for continuous variables, data are expressed as mean values and standard deviations. Ranges are expressed when data were not normally distributed. Differences between groups were compared using unpaired, 2-sided Student $t$ tests for continuous variables. The chi-square test or Fisher's exact test was used for categoric variables. Data were analyzed using SPSS software (Version 13.0; SPSS Inc, Chicago, Ill).

\section{RESULTS}

\section{General Characteristics}

There was no difference in gender, age, or body weight distribution between groups A and B (Table 2). The average diameter of the ASD in all patients was $26.9 \pm 6.1 \mathrm{~mm}$ (5-44 mm), with group A having a significantly larger ASD diameter $(33.6 \pm 4.5$; range, $12-44 \mathrm{~mm} ; P<.001)$. In group A, the ASDs of 89 patients $(70.6 \%)$ were larger than $30 \mathrm{~mm}(P<.001$, compared with group B). Most of the ASDs in group B were the central type. Group A had a greater heterogeneous mix of ASD type and more superior vena cava, inferior vena cava, and blending type than group B $(P<.01)$.

\section{Analysis of the Transthoracic Occlusion Group Unsuitable for Transcatheter Occlusion}

A total of 126 patients were deemed unsuitable for TCO treatment by inclusion criteria. These patients (assigned to group A) satisfied TTO inclusion criteria and underwent 
TABLE 1. Inclusion criteria of patients selected for transcatheter occlusion and transthoracic occlusion

\begin{tabular}{|c|c|c|}
\hline & $\begin{array}{c}\text { Inclusion criteria } \\
\text { of TCO }\end{array}$ & $\begin{array}{c}\text { Inclusion criteria } \\
\text { of TTO }\end{array}$ \\
\hline Age & $\geq 3 \mathrm{y}$ & $\geq 2 \mathrm{y}$ \\
\hline $\begin{array}{l}\text { Clinical } \\
\quad \text { manifestation }\end{array}$ & $\begin{array}{l}\text { Symptomatic or } \\
\text { signs of right } \\
\text { ventricular } \\
\text { volume overload }\end{array}$ & Same as TCO \\
\hline \multicolumn{3}{|l|}{ Morphology of ASD } \\
\hline Size & $\begin{array}{l}\leq 36 \mathrm{~mm} \text { in adults } \\
\text { and smaller in young } \\
\text { children according } \\
\text { to femoral vessel }\end{array}$ & No limitation \\
\hline Type & Mainly central & No limitation \\
\hline Rim measurements & & $\begin{array}{l}\text { Generally no more } \\
\text { than } 2 \text { rims } \\
\leq 5 \mathrm{~mm} \\
\text { in } 1 \text { patient }\end{array}$ \\
\hline $\begin{array}{l}\text { Inferior-posterior rim } \\
\quad \text { (toward IVC) }\end{array}$ & $\geq 5 \mathrm{~mm}$ & 0 \\
\hline $\begin{array}{l}\text { Superior-posterior rim } \\
\text { (toward SVC) }\end{array}$ & $\geq 5 \mathrm{~mm}$ & $\geq 2 \mathrm{~mm}$ \\
\hline $\begin{array}{l}\text { Posterior rim } \\
\quad \text { (toward PV) }\end{array}$ & $\geq 5 \mathrm{~mm}$ & $\geq 2 \mathrm{~mm}$ \\
\hline $\begin{array}{l}\text { Inferior rim } \\
\quad \text { (toward } \mathrm{AV})\end{array}$ & $\geq 5 \mathrm{~mm}$ & $\geq 2 \mathrm{~mm}$ \\
\hline $\begin{array}{l}\text { Anterior-superior rim } \\
\text { (toward AR) }\end{array}$ & $\geq 2 \mathrm{~mm}$ & 0 \\
\hline Coronary sinus rim & $\geq 5 \mathrm{~mm}$ & $\geq 5 \mathrm{~mm}$ \\
\hline
\end{tabular}

TTO. More than half of these 126 patients $(57.1 \%, 72 / 126)$ were unsuitable for TCO because of ASD lesions with diminutive rims, especially inferiorly $(48.6 \%, 35 / 72)$. In group A, 27.8\% (35/126) did not receive TCO because of oversized ASD lesions (of these, 24 patients had ASD lesions $>36 \mathrm{~mm}$, the absolute upper limit cutoff, and the remaining 11 patients had oversized ASD lesions relative to the circumference of their femoral vessels). In group A, $5.6 \%(7 / 126)$ were unsuitable for TCO because of interatrial septal floppiness or rim softness, including 3 patients who had failed previous TCO attempts. Peripheral vascular diseases $(2.4 \%, 3 / 126)$, allergy to contrast agent $(0.8 \%$, $1 / 126)$, and age less than 3 years $(6.3 \%, 8 / 126)$ were the factors accounting for TCO unsuitability in the remaining patients in group A (Table 3).

\section{Intraoperative Results}

Successful implantation of the ASD occluder device was achieved in 265 patients $(98.9 \%$ ), including 15 patients with double ASDs occluded with a single device through the larger defect. Correct placement of the device without redeployment was achieved in 249 patients $(92.9 \%)$. TTO failed in 3 patients who immediately underwent cardiac bypass surgery. In 1 patient (group A), the ASD occluder was displaced into the right ventricular outlet after release. We immediately lengthened the incision in the fourth intercostal space and performed open surgery to remove the device and repair the ASD under CPB. Two patients (1 from each group) were transferred to $\mathrm{CPB}$ surgery because of unstable implanted ASD occlusions as verified by the push-pull maneuver. In these 3 patients, ASD-CPB surgical repair was successful and uneventful.

In total, 256 circular and 9 elliptical devices were used. The mean size of all implanted circular devices was 30.4 $\pm 5.5 \mathrm{~mm}$ (range, $10-48 \mathrm{~mm}$ ). The average size of circular occluders in group A was $38.2 \pm 4.2 \mathrm{~mm}$ (range, 22-48 $\mathrm{mm})$, larger than in group B $(24.0 \pm 4.5 \mathrm{~mm}$; range, $22-48 \mathrm{~mm})(P<.001)$. Elliptical occluders were used only in group $\mathrm{A}$.

We listed the 2 typical patients with elliptical devices: In 1 female patient with an elliptical ASD $14 \times 32 \mathrm{~mm}$, the rim to aortic root, aortic valve, and right pulmonary vein was $0 \mathrm{~mm}, 3 \mathrm{~mm}$, and $2 \mathrm{~mm}$, respectively. We chose an $18 \times 36-\mathrm{mm}$ elliptical device that successfully occluded the ASD. In 1 female patient with an elliptical ASD $25 \times 15 \mathrm{~mm}$, the rim to aortic root and aortic valve was $0 \mathrm{~mm}$ and $5 \mathrm{~mm}$, respectively. We first placed a $30-\mathrm{mm}$ circular occluder; however, atrioventricular conduction blocking occurred, so we redeployed a $16 \times 32-\mathrm{mm}$ elliptical occluder, and the atrioventricular conduction blocking recovered automatically.

The average procedure time for all study patients was $37.2 \pm 9.2$ minutes (range, $34-81$ minutes). The average intracardiac manipulation time was $5.8 \pm 3.0$ minutes (range, 1-48 minutes), with no statistically significant difference between groups.

\section{Postoperative Results}

All patients were transferred to the ICU for extubation and postoperative recovery. The average mechanical support time was $2.2 \pm 1.3$ hours (range, 1.8-4.0 hours). The average length of stay in the ICU and hospital was $6.3 \pm 4.2$ hours (range, 4.0-11.2 hours) and $3.2 \pm 0.8$ days (range, $2-7$ days), respectively. No statistically significant difference existed between the 2 groups with respect to these postoperative data (Table 4).

\section{Follow-up}

The total follow-up period ranged from 6 to 93 months (median, 43 months). Follow-up results (physical examination and transthoracic echocardiograms) were available for analysis in 260 patients at 1 month, 237 patients at 3 months, 195 patients at 1 year, 140 patients at 2 years, 92 patients at 4 years, and 69 patients at more than 6 years. Table 5 lists the early (occurring within 30 days of operation) and late (occurring $>30$ days postoperative) 


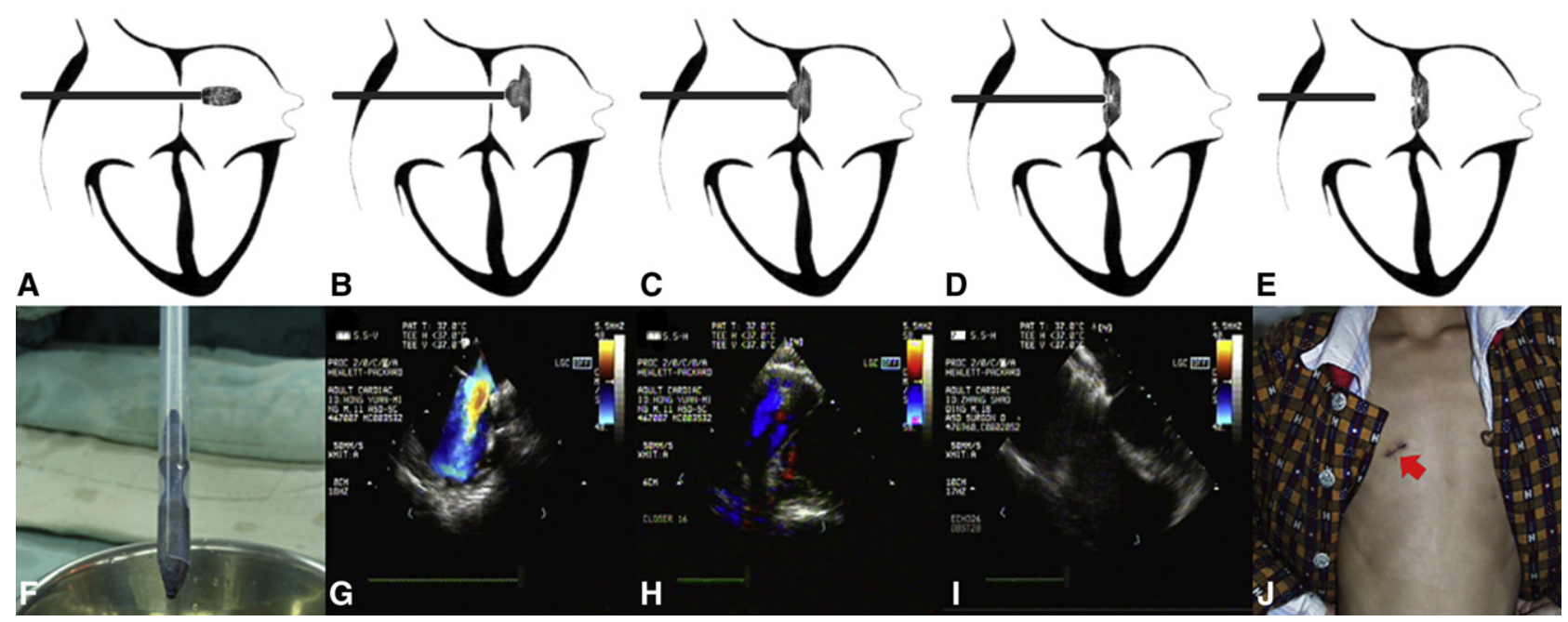

FIGURE 1. Schematic for the main steps of TTO. A, Under TEE guidance, the sheath is inserted through a right atrial puncture and ASD. B, The atrial disc is extruded in the left atrial and adjusted to be parallel with the atrial septum. C, The sheath and cable are withdrawn until the occlusion disc joins the atrial septum. D, Confirm via a repeated push-pull maneuver. E, The sheath is withdrawn if satisfactory ASD occlusion is achieved. F, The selected occlusion device in a straight sheath. G-I, TEE guidance during the process of ASD occlusion. J, An approximate 2.0 incision left before discharge.

complications identified in the follow-up period. Small residual shunts $(<2 \mathrm{~mm})$ were found by TTE before discharge in 3 patients with double-orifice ASDs. All these residual shunts closed during follow-up (at 3, 9, and 16 months). Congestive heart failure developed in 4 patients ( 3 in group A) in the ICU, and they recovered by discharge. No heart perforation or device embolization occurred in any patient during the entire follow-up period. No statistically significant difference in the occurrence of early or late complications was found between the 2 groups.

\section{DISCUSSION}

The ASD is one of the most common congenital heart diseases. TTO of ASD, different from traditional surgical closure and TCO methods, is a new ingenious hybrid method for ASD closure. The present study reports the early and mid-term results of TTO for ASD occlusion in 268 patients, of whom 126 were considered unsuitable for TCO.

\section{Safety and Efficacy of Transthoracic Occlusion}

Currently, the mortality of any method for ASD closure is close to zero. ${ }^{1}$ However, both CPB surgical closure and TCO of ASD are associated with morbidity. ${ }^{8,13}$ Conventional surgery carries the consequence of operative trauma, an unsightly scar, and CPB-related deleterious effects. ${ }^{14,15}$ Device embolization, residual shunt, vessel injury, and perforation of the heart have been reported in cases of TCO of ASD. Complication rates for CPB

TABLE 2. Patient characteristics

\begin{tabular}{|c|c|c|c|c|}
\hline & All patients & Group A & Group B & $P$ value \\
\hline No. of patients & 268 & 126 & 142 & \\
\hline \multicolumn{5}{|l|}{ Gender } \\
\hline Male/female & $97 / 171$ & $45 / 81$ & $52 / 90$ & .878 \\
\hline Mean age (y, SD, range) & $15.9(8.2), 2-65$ & $15.4(9.3), 2-65$ & $16.3(8.8), 2-2$ & .928 \\
\hline Mean BW ( $\mathrm{kg}, \mathrm{SD}$, range) & 36.5 (12.7), 12.5-81.8 & 38.8 (14.5), 12.5-72.2 & 34.5 (11.6), 13.0-81.8 & .837 \\
\hline \multicolumn{5}{|l|}{ Morphology of ASD } \\
\hline Size (mm, SD, range) & $26.9(6.1), 5-44$ & $33.6(4.5), 12-44$ & $21.0(5.1), 5-38$ & $<.001$ \\
\hline$>30 \mathrm{~mm}$ & $127(47.4 \%)$ & $89(70.6 \%)$ & $38(26.8 \%)$ & $<.001$ \\
\hline \multicolumn{5}{|l|}{ Type } \\
\hline Central & $187(69.8 \%)$ & $53(42.1 \%)$ & $134(94.4 \%)$ & $<.001$ \\
\hline SVC & $22(8.2 \%)$ & $17(13.5 \%)$ & $5(3.5 \%)$ & .003 \\
\hline IVC & $39(14.6 \%)$ & $36(28.6 \%)$ & $3(2.1 \%)$ & $<.001$ \\
\hline Blending & $20(7.5 \%)$ & $20(15.9 \%)$ & $0(0 \%)$ & $<.001$ \\
\hline Double orifice & $15(5.6 \%)$ & $9(7.1 \%)$ & $6(4.2 \%)$ & .300 \\
\hline Aneurysm of IAS & $15(5.6 \%)$ & $7(5.6 \%)$ & $8(5.6 \%)$ & .978 \\
\hline
\end{tabular}

$S D$, Standard deviation; $B W$, body weight; $A S D$, atrial septal defect; $S V C$, superior vena cava; $I V C$, inferior vena cava; $I A S$, interatrial septum. 
TABLE 3. Analysis of the reasons for transcatheter occlusion unsuitability in the transthoracic occlusion group

\begin{tabular}{lc}
\hline \multicolumn{1}{c}{ Main reasons } & No. of patients \\
\hline Age $(<3$ y) & $8(6.3 \%)$ \\
Size & $35(27.8 \%)$ \\
$\quad$ Diameter $>36 \mathrm{~mm}^{*}$ & 24 \\
Relatively oversized* & 11 \\
Rim & $72(57.1 \%)$ \\
Superior-posterior rim (toward SVC) & 4 \\
Posterior rim (toward PV) & 19 \\
Inferior rim (toward AV) & 35 \\
$\quad$ Anterior-superior rim (toward AR) & 14 \\
IAS $\dagger$ & $7(5.6 \%)$ \\
Peripheral vascular disease & $3(2.4 \%)$ \\
Allergic to radiography agent & $1(0.8 \%)$ \\
Total & 126 \\
\hline
\end{tabular}

$S V C$, Superior vena cava; $P V$, pulmonary vein; $A V$, aortic vein; $A R$, aortic root; $I A S$, interatrial septum. *Oversized: ASD requiring an occluder with sheath size larger than patient's femoral vein diameter. †IAS too floppy/soft.

surgery and TCO have been reported as $24 \%$ and $7 \%$, respectively. ${ }^{2}$ Vida and colleagues ${ }^{16}$ reported early complication rates for surgery and TCO as $10.7 \%$ and $4.1 \%$, respectively, with a complete closure rate of $87.5 \%$ for both modalities together. Majunke and colleagues ${ }^{17}$ reported 2 device embolizations and 6 patients requiring emergency or elective surgery in 572 patients who underwent TCO.

In 2002, we reported the promising clinical results of the earliest 33 patients undergoing TTO closure of ASD. ${ }^{10}$ Six years later, Tao and colleagues ${ }^{11}$ reported updated results of 53 patients; only 1 patient had a minimal residual shunt that resolved without complication. Hongxin and colleagues ${ }^{12}$ reported 1 patient with a moderate residual shunt during follow-up. In the present study, there was zero mortality in the 268 patients investigated. The complete closure rate was $98.9 \%$. No severe complications occurred during the perioperative period or in the 8 years of postoperative follow-up. No reoperation was necessary for any patient. In addition to the data demonstrating a short average procedure and intracardiac manipulation time with TTO, $47 \%$ patients in our study were deemed unsuitable for TCO treatment. No randomized comparisons of TCO versus TTO for ASD occlusion are currently available, but our study's results are strongly convincing as to the utility, safety, and efficacy of TTO.

\section{Differences Between Inclusion Criteria of Transthoracic Occlusion and Transcatheter Occlusion}

Patient selection is vital for prediction of successful occlusion and repair of ASD. Generally, secundum ASDs suitable for percutaneous closure should be $35 \mathrm{~mm}$ or less (some authors suggest a maximal stretch diameter of $36-38 \mathrm{~mm}$ ) in stretched balloon diameter, with a sufficient $(>5 \mathrm{~mm})$ rim of surrounding atrial tissue. ${ }^{1,4,8}$

In the present study, TTO inclusion criteria were formulated on the basis of our experience. Our TTO inclusion criteria broadened the currently accepted general criteria for TCO repair of ASD by decreasing rim length requirements and eliminating any ASD size limitation. The most common cause of TCO exclusion is too short an ASD rim length, especially the inferior rim. Large ASD size is the second most common reason for TCO exclusion, including an absolute upper limit cutoff size greater than $36 \mathrm{~mm}$ and a relative oversize (ASD requires an occluder with a sheath size larger than a patient's femoral vein diameter). The third most common reason for TCO exclusion is intra-atrial septal floppiness or rim softness prohibitive for TCO repair (the cause of previously failed TCO attempts in 3 patients). Infrequent causes of TCO exclusion included peripheral vascular disease and contrast agent allergy.

\section{Rationale for the Broader Transthoracic Occlusion Inclusion Criteria Over Transcatheter Occlusion}

The occluder delivery sheath is short, hard, and perpendicular to the ASD. It is easier to guide the sheath across

TABLE 4. Postoperative results and inpatient statistics

\begin{tabular}{|c|c|c|c|c|}
\hline & All patients & Group A & Group B & $P$ value \\
\hline Successful implantation & $265 / 268$ & $124 / 126$ & $141 / 142$ & .493 \\
\hline Rate of redeployment & $17 / 268$ & $11 / 126$ & $6 / 142$ & .131 \\
\hline Transferred to CS & 3 & 2 & 1 & .132 \\
\hline \multicolumn{5}{|l|}{ Size of device } \\
\hline Circular diameter (mm, SD, range) & $25630.4(5.5), 10-48$ & 11538.2 (4.2), 22-48 & $14124.0(4.5), 10-42$ & $<.001$ \\
\hline \multirow[t]{3}{*}{ Elliptical } & 9 & 9 & 0 & .001 \\
\hline & $16-28 \mathrm{~mm}$ in radial & $16-28 \mathrm{~mm}$ in radial & & \\
\hline & $32-46 \mathrm{~mm}$ in longitudinal & $32-46 \mathrm{~mm}$ in longitudinal & & \\
\hline Mean IMT (min, SD, range) & $5.8(3.0), 1-48$ & $6.8(3.4), 2-48$ & $5.0(4.2), 1-35$ & .321 \\
\hline Mean TOT (min, SD, range) & $37.2(9.2), 34-81$ & 37.9 (10.9), 36-75 & $36.6(8.7) 34-81$ & .912 \\
\hline Mean MST (h, SD, range) & $2.2(1.3), 1.8-4.0$ & $2.3(1.4), 1.9-3.9$ & $2.1(1.1), 1.8-4.0$ & .297 \\
\hline Duration in ICU ( $h, S D$, range) & $6.3(4.2), 4.0-11.2$ & $6.9(4.1), 4.0-11.2$ & $5.8(3.7), 4.3-10.5$ & .554 \\
\hline Duration in hospital (d, SD, range) & $3.2(0.8), 2-7$ & $3.1(1.3), 2-7$ & $3.3(1.0), 2-6$ & .218 \\
\hline
\end{tabular}


TABLE 5. Early* and late complications

\begin{tabular}{lcccc}
\hline & $\begin{array}{c}\text { All patients } \\
(\mathbf{n = 2 6 8})\end{array}$ & $\begin{array}{c}\text { Group A } \\
(\mathbf{n = 1 2 6})\end{array}$ & $\begin{array}{c}\text { Group B } \\
(\mathbf{n}=\mathbf{1 4 2})\end{array}$ & $\begin{array}{c}\boldsymbol{P} \\
\text { value }\end{array}$ \\
\hline Early complications (total) & 18 & 10 & 8 & .452 \\
$\quad$ IAVB & 3 & 2 & 1 & .493 \\
Residual shunt & 3 & 2 & 1 & .493 \\
Atrial fibrillation & 1 & 1 & 0 & .288 \\
Heart failure & 4 & 3 & 1 & .259 \\
PPCS & 3 & 1 & 2 & .633 \\
Pleural effusion & 3 & 1 & 2 & .633 \\
Pericardial effusion & 1 & 0 & 1 & .345 \\
Late complications (total) & 7 & 4 & 3 & .586 \\
Atrial fibrillation & 3 & 2 & 1 & .493 \\
PPCS & 3 & 1 & 2 & .633 \\
Pleural effusion & 1 & 1 & 0 & .288 \\
Total complications & 25 & 14 & 11 & .345 \\
\hline CS, Conver
\end{tabular}

$C S$, Conventional surgery; TSVT, transient supraventricular tachycardia; IAVB, incomplete atrioventricular block; PPCS, post-pericardiotomy syndrome. *Events occurring within $30 \mathrm{~d}$ after occlusion were considered early.

the defects and adjust the device for proper anchoring. For patients with a large ASD of short rim measurements, the surgeon is able to push the sheath by hand against the short rim and deploy the device into proper position. The surgeon is also able to use a powerful push-pull maneuver through the delivery cable to confirm device stability. However, for TCO, the delivery sheath is long and soft, and there is a 450-degree angle between the septum and the inferior vena cava. When the entire system is withdrawn, the sheath and device move inferiorly toward the inferior vena cava, rather than in the ideal left to right direction. Kutty and colleagues ${ }^{18}$ and Nounou and colleagues ${ }^{19}$ tried to improve the delivery system by changing the guide catheter or angle of the attached occluder device, but it remains difficult to achieve the ideal perpendicular approach and impossible to perform the push-pull maneuver via TCO.

The shape and stiffness of the TTO occluder itself have certain advantages over those used in TCO. To our knowledge, the elliptical occluder used in our study is the first and only reported device of its kind. The anatomic shape of the ASD is more elliptical than it is round. If the longitudinal diameter is not significantly larger than the radial diameter of the ASD, a circular occluder can be used to repair the ASD. However, if the longitudinal diameter is much longer than the radial diameter $(\geq 2 \times)$, a round occluder will encroach severely on tissues in the radial aspects; it is well known that the atrioventricular node and attachment of the mitral valve regularly inhabit this region. The transcatheter approach uses a long and soft delivery sheath that cannot implant asymmetric occluders. Also, the occluders used in the present study are harder than the Amplazer's septal occluder. Our results demonstrated that the harder occluder did not increase the complication of erosion, perhaps because most of the erosion occurred as the result of instability of the implanted device. The relative movement between the device and the surrounding structures can cause the chronic damage and erosion. The increased stiffness could help the 2 edges of the device clamp the rim of ASD more tightly. ${ }^{20}$

TEE plays an important role in TTO. TEE can provide real-time Doppler feedback of the existing ASD shunt, help guide adjustment of the occluder's position, and confirm a successfully closed ASD during repeated push-pull maneuvers. In addition, TEE can evaluate the hardness of the rims surrounding the ASD by the strength of echo reflection; certain soft rims will require a larger occluder device. $^{20}$

TTO extends inclusion criteria to the pediatric population. In young children, the femoral vessel diameter is proportionally small compared with ASD size. Even with considerations of femoral vascularelasticity, ${ }^{21,22}$ if the ASD is large, the vessel is apt to be injured. However, the intercostal space is large enough to transfer the delivery sheath in children at least 2 years old. Therefore, the TTO method provides a manner of ASD closure to a greater pediatric population with larger ASD dimensions.

TTO procedures are performed in cardiac surgery operation rooms, where CPB is readily available. Patients are endotracheally intubated under general anesthesia. In the event of a failed occlusion, device embolization, hemorrhage, or malignant arrhythmia, the patient would be directly converted to CPB surgery. This safety net broadened the potential to attempt TTO in even difficult ASD cases.

According to the results of the present study, TTO is safe and efficacious with the advantages discussed. In addition, because TTO is relatively easy to learn, there is a swifter learning curve for the technique. TTO does not require fluoroscopy, eliminating the potential for radiation injury or sequelae. Perhaps the most outstanding aspect of TTO of ASD is its practical utility in patients deemed unsuitable for TCO management. Our follow-up results demonstrate that approximately $5.5 \%$ of patients could avoid CPB operation by undergoing TTO. On the basis of the high morbidity of ASD, many patients are in this category, and we believe TTO, with its unique advantages, will have increased importance and application in the future of ASD treatment.

\section{Study Limitations}

This was a retrospective study and is limited because it was not a randomized, controlled double-blinded study. It is difficult to perform a randomized and double-blinded study for ASD closure for obvious ethical and logistic reasons. Both TCO and conventional CPB surgeries were performed during the study period, but the present study did not compare TTO with TCO or conventional surgery. The different inclusion criteria for patients suitable for TTO, TCO, and conventional surgical repair of ASD make a comparison analysis of patient outcomes difficult. 
The present study compared the results of 2 patient groups deemed fit or unfit for TCO ASD repair, and the follow-up results from both 2 groups are equally outstanding.

\section{CONCLUSIONS}

TTO, a novel method of ASD treatment pioneered by the Institute of Cardiovascular Surgery, is safe and relatively easy to perform, and carries low morbidity. Most important, TTO has a role in successfully treating ASD lesions that are unsuitable for the TCO method. With its record of safety and efficacy, TTO is currently being performed in many institutions in China and will likely be applied more widely for ASD treatment in the future.

\section{References}

1. Lindsey JB, Hillis LD. Clinical update: atrial septal defect in adults. Lancet. 2007;369:1244-6.

2. Du ZD, Hijazi ZM, Kleinman CS, Silverman NH, Larntz K. Comparison between transcatheter and surgical closure of secundum atrial septal defect in children and adults: results of a multicenter nonrandomized trial. J Am Coll Cardiol. 2002;39:1836-44

3. Mills NL, King TD. Nonoperative closure of left-to-right shunts. J Thorac Cardiovasc Surg. 1976;72:371-8.

4. Marie Valente A, Rhodes JF. Current indications and contraindications for transcatheter atrial septal defect and patent foramen ovale device closure. Am Heart J. 2007; 153:81-4

5. Chessa M, Carminati M, Butera G, et al. Early and late complications associated with transcatheter occlusion of secundum atrial septal defect. J Am Coll Cardiol. 2002;39:1061-5.

6. Divekar A, Gaamangwe T, Shaikh N, Raabe M, Ducas J. Cardiac perforation after device closure of atrial septal defects with the Amplatzer septal occluder. J Am Coll Cardiol. 2005;45:1213-8.

7. Gadhinglajkar S, Sreedhar R. Transoesophageal echocardiography during surgery for atrial septal defect with partial anomalous pulmonary venous connection. Ann Card Anaesth. 2008;11:140-1.
8. Webb G, Gatzoulis MA. Atrial septal defects in the adult: recent progress and overview. Circulation. 2006;114:1645-53.

9. Kang Y, Cai Z, Chen Y, Bai X, Shao J. Video-assisted thoracoscopic cardiac surgery in closure of atrial septal defect without extracorporeal circulation. J 4th Mil Med Univ. 2000;21:s197-8.

10. Yu S, Cai Z, Kang Y, et al. Closure of atrial septal defect with occluder by minimally invasive and non-extracorporeal circulation ways. Chin J Min Inv Surg. 2002;2:292-4.

11. Tao L, Zeng XJ, Ma XJ, Luo YH, Lim YP, Chua YL. The experience of occluding secundum atrial septal defect. Ann Thorac Surg. 2008;85:695.

12. Hongxin L, Wenbin G, Lijun S, et al. Intraoperative device closure of secundum atrial septal defect with a right anterior minithoracotomy in 100 patients. J Thorac Cardiovasc Surg. 2007;134:946-51.

13. Spies C, Khandelwal A, Timmermanns I, Schrader R. Incidence of atrial fibrillation following transcatheter closure of atrial septal defects in adults. Am J Cardiol. 2008;102:902-6.

14. Konstantinides S, Geibel A, Olschewski M, et al. A comparison of surgical and medical therapy for atrial septal defect in adults. N Engl J Med. 1995;333:469-73.

15. Berger F, Vogel M, Alexi-Meskishvili V, Lange PE. Comparison of results and complications of surgical and Amplatzer device closure of atrial septal defects. J Thorac Cardiovasc Surg. 1999;118:674-8.

16. Vida VL, Barnoya J, O'Connell M, Leon-Wyss J, Larrazabal LA, Castañeda AR. Surgical versus percutaneous occlusion of ostium secundum atrial septal defects: results and cost-effective considerations in a low-income country. J Am Coll Cardiol. 2006;47:326-31.

17. Majunke N, Bialkowski J, Wilson N, et al. Closure of atrial septal defect with the Amplatzer septal occluder in adults. Am J Cardiol. 2009;103:550-4.

18. Kutty S, Asnes JD, Srinath G, Preminger TJ, Prieto LR, Latson LA. Use of a straight, side-hole delivery sheath for improved delivery of Amplatzer ASD occluder. Catheter Cardiovasc Interv. 2007;69:15-20.

19. Nounou M, Harrison A, Kern M. A novel technique using a steerable guide catheter to successfully deliver an Amplatzer septal occluder to close an atrial septal defect. Catheter Cardiovasc Interv. 2008;72:994-7.

20. Zhang J, Li J, Li L, et al. Value of transthoracic echocardiography on guiding occlusion of hard-rim atrial septal defect. Chin J Ultrasonogr. 2006;15:182-5.

21. Butera G, De Rosa G, Chessa M, et al. Transcatheter closure of atrial septal defect in young children: results and follow-up. J Am Coll Cardiol. 2003;42:241-5.

22. Butera G, Romagnoli E, Carminati M, et al. Treatment of isolated secundum atrial septal defects: impact of age and defect morphology in 1,013 consecutive patients. Am Heart J. 2008;156:706-12. 